\title{
Regulation of Adult Neurogenesis and Plasticity by (Early) Stress, Glucocorticoids, and Inflammation
}

\author{
Paul J. Lucassen ${ }^{1}$, Charlotte A. Oomen ${ }^{1}$, Eva F.G. Naninck ${ }^{1}$, Carlos P. Fitzsimons ${ }^{1}$, \\ Anne-Marie van Dam², Boldizsár Czeh ${ }^{3,4}$, and Aniko Korosi ${ }^{1}$ \\ ${ }^{1}$ Centre for Neuroscience, Swammerdam Institute of Life Sciences, University of Amsterdam, \\ 1090 GE Amsterdam, The Netherlands \\ ${ }^{2}$ VU University Medical Center, Department of Anatomy \& Neurosciences, 1007 MB Amsterdam, \\ The Netherlands \\ ${ }^{3}$ MTA-PTE, Neurobiology of Stress Research Group, University of Pecs, 7624 Pecs, Hungary \\ ${ }^{4}$ Structural Neurobiology Research Group, Szentagothai Janos Research Center, University of Pecs, \\ 7624 Pecs, Hungary \\ Correspondence: p.j.lucassen@uva.nl
}

\begin{abstract}
Exposure to stress is one of the best-known negative regulators of adult neurogenesis (AN). We discuss changes in neurogenesis in relation to exposure to stress, glucocorticoid hormones, and inflammation, with a particular focus on early development and on lasting effects of stress. Although the effects of acute and mild stress on AN are generally brief and can be quickly overcome, chronic exposure or more severe forms of stress can induce longer lasting reductions in neurogenesis that can, however, in part, be overcome by subsequent exposure to exercise, drugs targeting the stress system, and some antidepressants. Exposure to stress, particularly during the sensitive period of early life, may (re)program brain plasticity, in particular, in the hippocampus. This may increase the risk to develop cognitive or anxiety symptoms, common to brain diseases like dementia and depression in which plasticity changes occur, and a normalization of neurogenesis may be required for a successful treatment response and recovery.
\end{abstract}

\section{STRESS AND THE STRESS RESPONSE}

Environmental challenges are part of our daily Elives. In many instances, challenges can trigger stress responses in an individual. Even though stress is often perceived as being increasingly present in our modern and demanding industrialized society, the stress system itself is a very old and essential alarm system that enables an individual to adapt and respond to any (perceived or real) threat in its environment. Well conserved in evolution, yet highly sophisticated, the stress system is activated in the brain and body whenever a discrepancy occurs between the expectation of an organism and the reality it encounters and when its homeostasis is threatened.

Editors: Fred H. Gage, Gerd Kempermann, and Hongjun Song

Additional Perspectives on Neurogenesis available at www.cshperspectives.org

Copyright (C) 2015 Cold Spring Harbor Laboratory Press; all rights reserved; doi: 10.1101/cshperspect.a021303

Cite this article as Cold Spring Harb Perspect Biol 2015;7:a021303 
P.J. Lucassen et al.

\section{The Definition of Stress}

Stressors can be psychological in nature, as in the case of interpersonal, financial, and familial problems, a high psychosocial or job-related demand, a loss of control, or lack of information, which cause uncertainty about the future outcome of a given situation or event (Ursin and Eriksen 2004). Physical and more biological changes, like severe blood loss or dehydration, metabolic crises, or systemic inflammation, can also elicit stress responses. On exposure to a stressor, various sensory and cognitive signals converge that trigger multiple processes in the body and brain that help the individual to regain homeostasis.

Stress is no single entity and different types are distinguished. Stress can be acute (e.g., being confronted with a predator) or chronic (living in poverty or in a broken family). It may occur only once, or may rather take place in a repetitive manner that can eventually be anticipated. Stress can be unpredictable and uncontrollable, mild or severe, and occurring in or out of context (e.g., of a learning experience). The perception of these stressors, and the magnitude and duration of an individual's response to it varies considerably and depends to a large extent on genetic background, sex, coping strategies, and personality traits. Early life (EL) experiences, epigenetics, and gene-environmental interactions are also important (Joels et al. 2007, 2012; Koolhaas et al. 2011; Kim et al. 2013; Lucassen et al. 2013b). Importantly, stress responses also occur following rewarding, "positive" and/or appetitive stimuli (e.g., winning a competition, sexual activity). Although they are often not considered as stressors in classic, generally "negative," terms, the physiological responses they elicit can be as large as those seen after more aversive stimuli. Here, stress is defined as any environmental demand that exceeds the physiological regulatory capacity of an organism, in particular, during situations of unpredictability and uncontrollability. Hans Selye already noted early on that the effects of stress are generally first perceived and evaluated via the brain and then develop in a stereotypic manner. Thus, in response to a stressor, various signals converge to orchestrate together an integrated response that "resets" many peripheral and central processes and allows an individual to adapt and, thereby, to restore and maintain homeostasis.

Time Domains and Mediators of the Stress Response

The physiological stress response can be divided into a very quick and a more delayed response. The first phase of the stress response, the "alarm reaction," or the "fight-fright-or-flight" response, involves a rapid activation of the autonomic nervous system (ANS) that causes epinephrine and norepinephrine release from the adrenal medulla. These hormones quickly elevate basal metabolic rate, blood pressure, and respiration, and increase blood flow to the organs essential for the "fight-or-flight" response, such as heart and muscles. At a later stage, the hypothalamic-pituitary-adrenal (HPA) axis is activated as well. In this classic neuroendocrine circuit, limbic and hypothalamic brain structures coordinate emotional, cognitive, neuroendocrine, and autonomic inputs, which together determine the magnitude and specificity of an individual's behavioral, neural, and hormonal responses to stress (Joels and Baram 2009; Joels et al. 2012).

This second HPA response is mediated by glucocorticoid (GC) hormones (corticosterone in rodents and cortisol in humans). These steroid hormones are transcriptional regulators of GC-responsive genes and, thus, act in a slow, genomic manner. Nongenomic, much faster GC actions have also been described and their actions are mediated by membrane-bound receptors. It should be emphasized that other signaling pathways act in concert with the HPA axis, like the gonadal axis, the adipose-metabolic system, and the immune system. All of these help to (re)direct energy resources such that attention can be focused on the most urgent and important elements of the challenge. Consequently, other less urgent "maintenance" functions (e.g., food digestion or reproduction) are temporarily suppressed (Joels et al. 2012). 
HPA Axis, Stress, and Depression

Activation of the HPA axis is triggered by corticotropin-releasing hormone (CRH) in the paraventricular nucleus (PVN) that induces adrenocorticotropic hormone (ACTH) release from the pituitary, which, in turn, releases GCs from the adrenal. Regulation occurs through negative feedback after GC binding to high-affinity mineralocorticoid (MR) and lower affinity glucocorticoid receptors (GRs) (de Kloet et al. 2005). The GR helps to maintain GClevels within physiological limits (Kretz et al. 1999; Erdmann et al. 2008), and aberrant GR expression has been implicated in hypercortisolism, stress resistance, anxiety, and depression (de Kloet et al. 2005; Ridder et al. 2005; Wei et al. 2007). Furthermore, GC plasma levels are under strict circadian and ultradian control (Qian et al. 2012; Liston et al. 2013), which, together with GR and MR, determine sensitivity to stress (Sousa et al. 2008; Pruessner et al. 2010; Harris et al. 2013; Medina et al. 2013).

On their release in the periphery, GCs affect energy, inflammatory responses, and lipid metabolism, among others. Given the involvement of many organs and neuronal systems, imbalances in stress-hormone regulation can have deleterious consequences (de Kloet et al. 2005). This is particularly relevant for the brain, in which powerful corticosteroid hormones can influence memory, fear, and attention. Although acute and short-term stress is generally adaptive, exposure to chronic stress may cause an MR/GR imbalance or down-regulation (de Kloet et al. 2005; Qi et al. 2013), which can alter HPA feedback and results in overexposure of the brain and body to stress hormones and may increase the risk for psychopathology.

The large number of GRs in the brain and particularly in the hippocampus make this structure highly responsive to changes in stress hormones (de Kloet et al. 2005; Swaab et al. 2005; Wang et al. 2013; Lucassen et al. 2014). In contrast to the relative paucity of GRs in the rhesus monkey (Sánchez et al. 2000), the rodent and human hippocampus show abundant GR expression, both in CA1 and dentate gyrus (DG) neurons and astrocytes, although MRs are pres- ent in the hippocampus too. Both receptors have considerable genetic diversity in humans, and changes in GR/MR variants have been implicated in disorders related to chronic stress, like major depressive disorder (MDD) and in the associated reductions in hippocampal volume (Czéh and Lucassen 2007; Wang et al. 2012, 2013, 2014; Vinkers et al. 2014).

Functionally, chronic stress is associated with reductions in hippocampal excitability, long-term potentiation, and hippocampal memory, but positive effects of stress have been described too that depend on, among other factors, the timing, type, and controllability of a stressor (Joels et al. 2007, 2012). The morphological consequences of chronic stress include hippocampal volume reductions as well as a number of cellular changes, most notably dendritic atrophy and a suppressed rate of adult neurogenesis (AN) (see below) (Sapolsky et al. 1985, 1990; Lucassen et al. 2014).

\section{ADULT NEUROGENESIS}

AN refers to the production of new neurons, derived from stem cells present in the adult brain. Following different subsequential stages of proliferation, selection, fate specification, migration, and neuronal differentiation, new, functional neurons are eventually integrated into the pre-existing adult hippocampal network (Abrous et al. 2005; Zhao et al. 2008; Kempermann 2012; Jessberger and Gage 2014). AN is dynamically regulated by various environmental factors and declines with age. Indications of AN have also been reported in other brain structures like the amygdala, striatum, hypothalamus, and neocortex, with differences between species and often in response to specific challenges or injury. Neurogenesis in the DG is potently stimulated by exercise and environmental enrichment, parallel to changes in hippocampal function (Kempermann et al. 2010; Vivar et al. 2013). Rewarding experiences stimulate neurogenesis, and aversive experiences like stress generally decrease neurogenesis (Balu and Lucki 2009; Lucassen et al. 2010a). 
P.J. Lucassen et al.

Stress Regulates Adult Hippocampal Neurogenesis

Stress is one of the best-known environmental suppressors of AN. Both psychosocial (Gould et al. 1997; Czéh et al. 2002) and physical stressors (Malberg and Duman 2003; Pham et al. 2003; Vollmayr et al. 2003) can inhibit one or more phases of the neurogenesis process (Mirescu and Gould 2006; Lucassen et al. 2010a). In classical studies, rodents exposed to the odor of a predator generated a strong stress hormone response that was associated with significant reductions in hippocampal proliferation. Both acute and chronic stress exposure can suppress proliferation (Gould et al. 1997; Czéh et al. 2002; Heine et al. 2004a,b; Schoenfeld and Gould 2013; Wu et al. 2014), although different types of stress, including physical restraint, social defeat, inescapable foot shock, sleep deprivation, and mixed types of multiple, unpredictable, or mild stressors, also decrease numbers of new neurons in the DG. Interestingly, increases in neurogenesis have also been reported after stress in some instances, but in these studies, the stressors were predictable and mild and may actually have enriched an otherwise boring environment and could have been perceived as rewarding experiences (Parihar et al. 2011). In fact, reward, possibly mediated through dopamine, is known to enhance neurogenesis.

When no other transmitter systems are altered and the stressor is unpredictable and its nature severe, stress generally reduces neurogenesis. In fact, this type of stress can reduce multiple stages of the neurogenic process, including the initial phase of proliferation of the neural stem cells and amplifying progenitor cells, as well as subsequent neuronal differentiation phase and dendritic expansion. Stress not only reduces proliferation and neurogenesis in many different species, it may also shift neural stem cells away from neuronal differentiation and instead "redirect" them toward the generation of oligodendrocytes (Chetty et al. 2014). Although not studied in great detail yet, such stress-induced fate shifts may have important functional consequences, for example, for the myelination of axons and/or mossy fibers and, hence, network connectivity.
Although different types of stress trigger different behavioral and functional responses, the adrenal glucocorticoid hormones (GCHs, corticosterone in rodents, and cortisol in man) are considered the main common pathway that is instrumental in mediating the effects of stress on new neuron production (Schoenfeld and Gould 2013). Exogenous administration of GCs to animals has similar effects on cell proliferation, neuronal differentiation, and cell survival, as well as on the production of oligodendrocytes and microglia responses. Moreover, the reductions in neurogenesis after stress, and many molecular alterations as well (Datson et al. 2012), can be prevented by blocking GC release from the adrenal, or by blocking the GR or other HPA parameters using, for example, CRH antagonists (Alonso et al. 2003). Following a 3-wk exposure to multiple unpredictable stressors, a short treatment of 1 or 2 days with the GR antagonist mifepristone normalized the reduction in hippocampal neurogenesis (Mayer et al. 2006; Oomen et al. 2007; Hu et al. 2012).

Although more information has become available on its molecular control (Schouten et al. 2012; Anacker et al. 2013; Fitzsimons et al. 2013; Miller et al. 2013), the precise mechanism by which GCs decrease the number of new neurons remains unknown, but $N$-methyl-D-aspartate (NMDA) receptors, GRs and MRs, are present on the new cells, albeit in different ratios over time, and they likely act in concert to mediate effects of stress on the neurogenic process (Montaron et al. 2003; Wong and Herbert 2004, 2005). Notably, GR knockdown, selectively in cells of the hippocampal neurogenic niche, accelerates their neuronal differentiation and migration. GR knockdown further induced ectopic positioning of a subset of the new granule cells, altered their dendritic complexity, and increased their number of mature dendritic spines. Consistent with the increase in synaptic contacts, newborn cells with GR knockdown show increased basal excitability, parallel to impaired contextual freezing during fear conditioning (Fitzsimons et al. 2013). Hence, GR expression in the newborn hippocampal cells is important in mediating synaptic connectivity, structural as well as functional integration into 
the mature hippocampal circuits involved in fear memory. Furthermore, the precursors are located close to blood vessels. This proximity suggests a strong interaction with the vasculature, which is of relevance as it is indeed this population that is particularly sensitive to stress (Heine et al. 2005). Also, astrocytes are important as this cell type supports the survival of developing neurons, possess GR, and are affected by some, but not all, types of stress (Czéh et al. 2006; Banasr and Duman 2008; Oomen et al. 2009).

Stress further slows down neuronal differentiation, as evidenced by the up-regulation of markers indicating cell-cycle arrest, the expression of immature neuronal markers, and related changes in granule cell dendritic trees. Furthermore, stress and the resulting rise in GCs reduce the survival of neurons produced before the stressful experience. Although the underlying mechanism is largely unknown, this is thought to be mediated by inhibitory effects of stress on the expression of neurotrophins and survivalpromoting factors like brain-derived neurotrophic factor (BDNF) (Schmidt and Duman 2007). The reduction in survival likely also involves microglia, which are known to phagocytose the new neurons in the DG (Sierra et al. 2010; Hinwood et al. 2012; Morris et al. 2013). Indeed, stress influences microglia numbers, as well as their responsivity, which may modulate their efficiency in cleaning up debris left behind by dead new neurons. Alternatively, microglia could play an active role in reducing new neuron survival, either by releasing cytokines with neurotoxic effects, or by actively engulfing new neurons before their demise.

Although a role for (nor)adrenaline has not been studied in detail with respect to the stressinduced suppression of neurogenesis, an important difference among several studies is whether GC levels remain elevated after the exposure to the stressor has ended. In some psychosocial stress models, the GC "milieu" is altered and GC levels remain elevated long term, which has stronger inhibitory effects on AN than apparently severe, but predictable, physical stressors like restraint (Wong and Herbert 2004). Several examples exist of a persistent and lasting inhibition of AN after an initial stressor, despite a later normalization of GC levels (e.g., Czéh et al. 2002; Mirescu and Gould 2006; Schoenfeld and Gould 2013). Also, GC levels can remain elevated after the onset of the first, often psychosocial, stressor that suppresses neurogenesis for prolonged periods. In other milder models of stress, stress hormone levels generally normalize, yet neurogenesis remains reduced (Van Bokhoven et al. 2011; Schoenfeld and Gould 2013). This suggests that, although GCs are involved in the initial suppression of proliferation, they are not always necessary for the maintenance of this effect.

When studying effects of stress on $\mathrm{AN}$ in laboratory conditions, it is further important to realize that many variables influence the outcome of such studies. Interindividual and gender differences in stress coping, handling, time of day at sacrifice, and previous exposure to stressful learning tasks can all influence stress responses and changes in neurogenesis (e.g., Holmes et al. 2004; Ehninger and Kempermann 2006). An interesting contradiction exists in this respect regarding the direction of the generally positive effect of exercise on AN. Exercise is generally associated with beneficial changes, also in its effects on mood (Ernst et al. 2006; Brené et al. 2007; Kannangara et al. 2011; Vivar et al. 2013) and known to potently increase neurogenesis. Paradoxically, GCs are also increased during running. Moreover, although initial effects of exercise on proliferation are stimulatory, prolonged running may activate the HPA axis and the opioid system, and down-regulate progenitor proliferation rate (Droste et al. 2003; Naylor et al. 2005; Lou et al. 2008). Hence, particularly when exercise is prolonged, it can develop into a stressor that reduces, or even overrules, its positive effects on AN (Droste et al. 2003). This appears to depend on duration of voluntary running as examples exist of extended exercise for over 6 months in young or middle-aged rodents that continued to stimulate neurogenesis (Kronenberg et al. 2006; Marlatt et al. 2012). Hence, positive stimuli for AN can be most effective when at least HPA axis activation is minimal.

One other explanation for differences among seemingly comparable studies is that, 
P.J. Lucassen et al.

in addition to stress hormones like GCs, other mediators of the stress system are changed that interact with the regulation of neurogenesis. Models using repeated injections with exogenous GCs to imitate the hypercortisolism found in depression exert negative feedback at the level of the pituitary and inhibit the endogenous production of GCs by the adrenal. As a result, ACTH and CRH levels are very low in GC-treated rodents, a condition that is in contrast to the endogenous HPA axis activation seen in chronically stressed animals and patients in which $\mathrm{CRH}$, ACTH, and GCs are elevated. A large number of other factors may also contribute to the stress-induced inhibition of AN, like the stressinduced increase in glutamate release via NMDA receptor activation (Gould et al. 1997; Nacher and McEwen 2006; Schoenfeld and Gould 2013).

Stress further affects various neurotransmitters implicated in the regulation of neurogenesis: $\gamma$-aminobutyric acid (GABA) (Ge et al.2007), serotonin (Djavadian 2004), noradrenalin (Joca et al. 2007), acetylcholine (BruelJungerman et al. 2011), and dopamine (e.g., Domínguez-Escribà et al. 2006; Takamura et al. 2014). Other neurotransmitter systems, such as the cannabinoids, opioids, nitric oxide, various neuropeptides, and gonadal steroids, may also contribute (e.g., see Galea 2008; Balu and Lucki 2009). Importantly, stress is well known to reduce the expression of several growth and neurotrophic factors, like BDNF, insulin-like growth factor 1 (IGF-1), nerve growth factor (NGF), epidermal growth factor (EGF), and vascular endothelial growth factor (VEGF), which can influence neurogenesis (e.g., see Schmidt and Duman 2007; Wilson et al. 2014).

Stress-induced reductions in proliferation could be the result of various causes. They may result from apoptosis of progenitor cells, but also from a slowing down of the cell cycle and induction of cell-cycle arrest. Consistent with this, reductions in proliferation after acute stress are paralleled by increases in apoptotic cells, although it is not yet known whether these cells represent newborn or mature neurons. Following chronic stress, both proliferation and apoptosis were reduced, and expression of the cell-cycle inhibitor p27Kip1 was increased. This indicated that more cells had entered cell-cycle arrest and, thus, that granule cell turnover had slowed down (Heine et al. 2004a).

Chronic stress can also affect proliferation of glial cells. This was shown in the medial prefrontal cortex of rats after social defeat, after chronic unpredictable stress, or after chronic corticosterone administration. Similarly, prolonged and elevated GC treatment inhibited NG2-positive cell proliferation, reflecting changes in oligodendrocyte precursors. Chronic stress also promotes structural remodeling of microglia and can enhance the release of proinflammatory cytokines from microglia. Finally, astrocytes are key components of the "neurogenic niche" that provides the necessary local microenvironment for the generation of neurons in specific brain areas. They support maturation and integration of newborn neurons, both physically and by releasing a cocktail of growth factors and cytokines. Because astrocytes also contain GRs and can be regulated by stress, this together implies that stress can also modulate neural progenitors through interactions with astrocytes (Wang et al. 2013; Vallières et al. 2002).

Stress-induced suppression of AN has been associated with impaired performance on various cognitive tasks that require the hippocampus, such as spatial navigation learning and object memory. It should be noted that stress has been shown to facilitate certain types of learning, but these effects are typically observed within a shorter time frame than what would be expected for the involvement of new neurons per se. In addition, there are always additional younger immature and excitable neurons, as well as the older, existing population of DG cells that may be sensitive too, and could contribute. Furthermore, stressful experiences have been shown to increase anxiety-like behaviors, including those measured with the elevated plus maze, open field, and novelty suppressed feeding tasks (see Oomen et al. 2014).

\section{Neurogenesis and Depression}

Antidepressants are well known to affect hippocampal neurogenesis, possibly also in the human brain. Given the technical limitations to 
visualize neurogenesis in vivo, only a few studies have addressed this issue in postmortem tissue. Reif et al. (2006) failed to find differences in the level of neural stem-cell proliferation in postmortem brain samples among patients suffering from MDD, bipolar disorder, schizophrenia, or control subjects. Antidepressants did not increase neural stem-cell proliferation but, unexpectedly, significantly reduced the number of newly formed cells found in schizophrenic patients. More recent studies (Boldrini et al. 2009, 2012; Lucassen et al. 2010b, 2014) compared progenitor and dividing cells and found that, in untreated depressed subjects, numbers of nestin-positive progenitors were significantly decreased. Both serotonin reuptake inhibitor (SSRI) and tricyclic antidepressant (TCA) treatment increased the number of nestin-positive progenitors, and TCAs had a robust stimulatory effect on the number of Ki-67-reactive dividing cells. These changes were reported in middleaged, but not older, depressed patients, possibly because of age-related differences in plasticity in these patients. In a recent postmortem study on MDD patients, the volume of the histologically defined DG was in fact 68\% larger in SSRI-treated depressed subjects, although SSRI treatment substantially increased neural progenitor cells (NPCs) in the DG. A more recent study by Huang et al. (2013) found smaller DG volumes at magnetic resonance imaging (MRI) in unmedicated depressed patients, although a postmortem analysis reported the same, which is consistent with the neurogenic hypothesis of depression. Interestingly, both subfield and posterior hippocampal volume reductions were only seen in unmedicated depression but were absent in patients treated with antidepressants. Although it is so far not simple to detect ongoing neurogenesis in vivo (Manganas et al. 2007), these data are consistent with preclinical studies demonstrating subregional specific and opposite effects of stress or depression and antidepressant treatment.

Although AN may, thus, not be essential for the development of depression, it may be required for clinically effective antidepressant treatment (Jacobs et al. 2000; Sahay and Hen 2007; Kempermann et al. 2008; Surget et al.
2008; Lucassen et al. 2010a,b). Hence, stimulation of neurogenesis has been regarded as a promising strategy for identifying new antidepressant targets. Accordingly, when tested in chronic stress paradigms, several candidate antidepressant compounds, like corticotrophinreleasing factor (CRF-1), vasopressin (V1b) or GR antagonist (Alonso et al. 2003; Oomen et al. 2007; Surget et al. 2008), tianeptine (Czéh et al. 2001), or selective neurokinin 1 (NK-1) receptor antagonists (Czéh et al. 2005), could indeed normalize inhibitory effects of stress on proliferation or neurogenesis.

Hippocampal volume loss is well documented in various psychopathologies and in patients with Cushing's disease or in subjects treated with synthetic GCs (Sousa et al. 1998; Bourdeau et al. 2002). Although depression was traditionally considered to have a neurochemical basis, structural connectivity and plasticity changes, including neurogenesis, may contribute to its etiology as well. Later studies have suggested that neurogenesis is implicated in antidepressant drug action (Perera et al. 2011; Surget et al. 2011), but it remains elusive how exactly newborn neurons contribute to mood and depression, besides their cognitive deficits, which are related, but not specific to mood disorders (Revest et al. 2009; Snyder et al. 2011; Anacker and Pariante 2012; Lehmann et al. 2013; Lucassen et al. 2013a,b).

Although a reduced rate of neurogenesis may reflect impaired hippocampal plasticity, reductions in AN per se (i.e., without the presence of stress), are unlikely to produce depression. Lasting and stress-related reductions in DG neurogenesis will, however, alter the average age and overall composition of the DG cell population, and thereby influence the properties and vulnerability of the hippocampal circuit, which may, in the long term, modify volume (Teicher et al. 2012). Indeed, hippocampal volume changes often coincide with stressful episodes in depressed patients, correlating with cognitive impairments. The hippocampus further provides negative feedback control of the HPA axis, in which neurogenesis is at least partly implicated. Initial disturbances in hippocampal neurogenesis or output may, thus, disturb feed- 
P.J. Lucassen et al.

back and, hence, amplify HPA-axis dysregulation, which is common in $\sim 50 \%$ of depressed patients. Because massive cell loss could not be demonstrated in the hippocampus, the observed hippocampal volume changes could be caused by (atrophy of) the somatodendritic or synaptic components, glia, or from changes in fluid balance (Lucassen et al. 2014). Another structural substrate responsive to stress is AN.

\section{LONG-LASTING EFFECTS OF PERINATAL STRESS EXPOSURE}

$\mathrm{AN}$ is sensitive to stress exposure during the EL period. The set point of HPA axis activity, and possibly also of neurogenesis regulation, is, on the one hand, programmed by genotype, but can be further modified by early development and epigenetic changes (Lucassen et al. 2013b). In humans, early life stressors (ELS) are among the strongest predisposing factors for developing psychopathology and cognitive decline later in life (Heim et al. 2008; Loman et al. 2010; Maselko et al. 2011; Baram et al. 2012; Teicher et al. 2012). In experimental conditions, ELS has been shown to affect emotional and cognitive functions as well. Indeed, stress reactivity is elevated and cognitive functions are impaired in rats exposed to ELS (Brunson et al. 2005; Aisa et al. 2007; Ivy et al. 2010; Oomen et al. 2010; Baram et al. 2012).

Are these alterations associated with changes in neurogenesis? Rodent studies over the past decades have shown that neurogenesis appears to be very sensitive to stress, particularly when stress occurs during the perinatal period (Korosi et al. 2012). Also, perinatal stress can induce reductions in $\mathrm{AN}$ in the offspring (Lemaire et al. 2000; Coe et al. 2003; Lucassen et al. 2009) (although exceptions have been reported [Tauber et al. 2008]). Such reductions may, in part, occur through epigenetic modifications, often in a sex-dependent manner (Lucassen et al. 2013b). Perinatal stress in male rats was generally found to suppress neurogenesis (Mirescu et al. 2004; Korosi et al. 2012). The effects appear to be region specific: prenatal stress impaired neurogenesis in the DG but not in the olfactory bulb (Belnoue et al. 2013). The overall effect of stress on neurogenesis also depends on the developmental stage during which the organism experiences stress. Thus, in utero exposure to stress or to a variety of pharmacological agents almost invariably reduces neurogenesis in adulthood (Korosi et al. 2012). Postnatal exposure to stress yields more variable results, and is modified by maternal and paternal factors, sex, genetic background, and epigenetic changes, although suppression of neurogenesis prevails here as well (Leuner et al. 2010; Lucassen et al. 2010a,b, 2013b; Koehl et al. 2012; Loi et al. 2014). Neuronal survival was decreased and apoptosis was increased in offspring of lowcaring mothers versus offspring of high-caring mothers (Weaver et al. 2002; Bredy et al. 2003). In addition, repeated maternal separation (MS) leads to transiently increased (Nair et al. 2007) and lastingly decreased levels of proliferation (Mirescu et al. 2004), without affecting neuronal survival (Mirescu et al. 2004; Greisen et al. 2005) in the DG of the offspring. MS alters the capacity of adult neural precursor cells to differentiate into neurons via methylation of retinoic acid receptor gene promoter (Lucassen et al. 2013a,b; Boku et al. 2015).

Similarly, maternal deprivation (MD) is found to transiently increase numbers of immature (doublecortin [DCX]-positive) neurons in rats at 3 wk of age (Oomen et al. 2009), ultimately leading to reduced proliferation throughout the full rostrocaudal axis of the DG, and reduced differentiation in the caudal part of the DG at $10 \mathrm{wk}$ of age (Oomen et al. 2009). The evidence presented above suggests that the ELS-induced reduced neurogenic capacity observed later in life might be caused by an increase in neurogenesis during the postnatal phase that might result in depletion of the neurogenic pool. More importantly, the consequences of EL environment depend on the moment at which neurogenesis is determined. When tested in adulthood or middle-age, cell proliferation and neurogenesis were usually found to be decreased. Yet, at earlier stages, for example, at P9 (Naninck et al. 2015), PND21 (Suri et al. 2013), neurogenesis in males is actually enhanced by ELS, as was BDNF expression and performance in a stressful version of the 
Morris water maze (Oomen et al. 2010, 2011). Apparently, EL adversity can transiently improve dentate functionality, possibly to allow the organism to survive in adverse conditions. However, in the long run, EL adversity seems to program structural plasticity such that it may become a disadvantage (Mirescu et al. 2004; Loman et al. 2010; Korosi et al. 2012), most notably under low to moderately stressful conditions. Interestingly, when tested under stressful conditions, experiencing MD rather improved learning memory in these rats. In fact, contextual learning was enhanced in both contextual and cued fear-conditioning tasks, and, in the presence of corticosterone, long-term potentiation (LTP) was facilitated in male but not female MD rats (Oomen et al. 2010, 2011).

These data suggest that adverse EL events might increase the sensitivity of the hippocampus to the future surrounding environment and, hence, prepare the organism to respond optimally to stressful contexts encountered later in life (Koehl et al. 2012). Levels of neurogenesis in MD rats re-exposed to stress in adulthood were not measured in these studies; however, these results at the functional level may indicate that postnatal stress affects the responsiveness of the DG plasticity to the surrounding environment. Overall, this gives rise to a significant negative correlation among the number of proliferating (Ki-67 or bromodeoxyuridine [BrdU]-positive cells) or DCX-positive neurons and age in male rodents. Strikingly, different effects of ELS on learning and memory and neurogenesis are seen in female rats. Although neurogenesis is enhanced at PND21 in male rats exposed to $24 \mathrm{~h}$ of MD at PND3, a strong suppression was reported in females. However, in females, the consequence of EL adversity for the number of DCX-positive cells subsides with age, resulting in an overall positive correlation between the number of DCX-positive cells and age. Similarly, in mice, chronic ELS affects male's cognitive function and rates of survival of adult-born neurons more robustly when compared with females (Lucassen et al. 2013a,b; Naninck et al. 2015).

Also, the effects of prenatal stress on neurogenesis are often sex dependent. Male rats show a brief period in adolescence during which neurogenesis, BDNF expression, and spatial learning are actually improved, possibly allowing the individual to temporarily compensate for the effects of EL adversity. Female rats do not show such a period of improved performance but rather show a very strong suppression of neurogenesis during the prepubertal period, which then subsides with age. Although the readouts studied were not always specific for neurogenesis, the consequences of this period of suppressed neurogenesis in females, though, may be long lasting. For instance, female rats exposed to $24 \mathrm{~h}$ of MD at PND3 showed a lower total number of mature granule cells in adulthood, potentially limiting the number of synaptic contacts that can be established in this region. Finally, it is important to mention that levels of neurogenesis are permanently affected also by other ELS not necessarily related to the mother-infant interaction alone. For example, ELS inflammation (Jakubs et al. 2008; Musaelyan et al. 2014), radiation therapy (Fukuda et al. 2005; Naylor et al. 2008; Hoffman and Yock 2009), anesthesia (Zhu et al. 2010), stroke (Spadafora et al. 2010), infection (Bland et al. 2010), and ethanol exposure (Singh et al. 2009) induce long-lasting effects on neurogenesis associated with late-onset cognitive impairment.

Thus, the studies described have shown that EL experiences during both pre- and postnatal development can bidirectionally alter hippocampal neuronal plasticity and synaptic integrity. This strongly supports the possibility that these structural changes might be involved in affected cognition. This has recently been supported by a novel causal statistical methodology demonstrating that cognitive impairments induced by ELS are largely neurogenesis-dependent (Naninck et al. 2015).

\section{STRESS-RELATED NEUROINFLAMMATION AND ITS ROLE IN REGULATING NEUROGENESIS}

As it elicits a peripheral defense of the body to injury or the entry of exogenous antigens, inflammation, in a way, also represents a stressor. Several studies have now shown that inflammation per se, as well as some of the cell types 
P.J. Lucassen et al.

involved (i.e., the glia cells), can also affect neurogenesis. Particularly microglia are considered instrumental in this (Sierra et al. 2010; Morrens et al. 2012; Morris et al. 2013; Kreisel et al. 2014; Musaelyan et al. 2014), given their homeostatic role in inflammatory signaling that may become maladaptive in the chronically stressed brain. Under physiological conditions, microglia show a ramified phenotype involved in homeostasis of brain functioning, and associated with the production of anti-inflammatory and neurotrophic factors. When primed, by ELS or challenged by pathogens or damaged during adult life, microglia can switch to an amoeboid phenotype thereby gaining macrophage-like properties, including phagocytosis of tissue debris, as well as initiation of tissue repair or rather produce cytokines that are detrimental for neuronal function and viability (Bilbo et al. 2007; Bilbo and Schwarz 2009; Bland et al. 2010).

Other evidence suggests that microglia can have a dual role and, depending on their state of activation, they can either inhibit or stimulate AN both in the intact and injured brain (Ekdahl et al. 2009). It is also conceivable that various functionally divergent subpopulations of microglia exist, some having pro-, others antineurogenic effects (Ekdahl et al. 2009). Specific subsets of cytokines can even be proneurogenic although others decrease neurogenesis through interleukin (IL)-1 $\beta$ (Kaneko et al. 2006; Zunszain et al. 2012). Proinflammatory mediators can further restrict neurogenesis (Iosif et al. 2006). The effect of stress on hippocampal neurogenesis may in part be mediated by proinflammatory cytokines. The HPA axis is not only activated by stress, but also during disease processes, and by proinflammatory cytokines, such as IL-6 or exogenous interferon (IFN)- $\alpha$ (Cassidy and O'Keane 2000). During inflammation, cells of the immune system produce proinflammatory cytokines, such as IL-1 and IL-6, which elicit various ( patho)physiological reactions, that together coordinate the "nonspecific symptoms of sickness" and activate the HPA axis (Berkenbosch et al. 1987); elevated GC levels are generally immunosuppressive and then prevent the immune system from overshooting. Thus, a clear bidirectional communi- cation exists between the immune and neuroendocrine system (Rhen and Cidlowski 2005).

ILs are also produced within the brain during ischemia, dementia, multiple sclerosis, and epilepsy (Skaper 2007; Ravizza et al. 2008). In most of these conditions, microglial cells produce ILs that are generally considered detrimental for neuronal viability, although ILs have also been implicated in processes, such as brain plasticity (Johansson et al. 2008; Spulber et al. 2008). Hence, neuroinflammation, defined by microglial activation and the presence of proinflammatory mediators, represents a stressor that may affect AN.

Inflammation and cytokine expression largely inhibit AN directly (Vallières et al. 2002; Monje et al. 2003; Zunszain et al. 2012; Musaelyan et al. 2014), although immune modulators like transforming growth factor (TGF) $\beta$ (Wachs et al. 2006) have a concentration-dependent proneurogenic potential in the adult brain (Battista et al. 2006). Other proinflammatory cytokines, such as TNF- $\alpha$ (Iosif et al. 2006) or IFN- $\gamma$ decrease AN through modulation of IL-1 (Kaneko et al. 2006). In addition, impairment of IL-1 $\beta$ action prevents the attenuated rate of AN in response to stress, supporting the idea that proinflammatory mediators and local cues in the brain play a role in restricting AN (Koo and Duman 2008; Zunszain et al. 2012).

Conversely, factors capable of affecting cell genesis can also influence microglial activation. As part of the neuroinflammatory response, activated microglia modulates the neurogenic niche, and, depending on whether they are activated by IL- 4 or by IFN- $\gamma$, microglia cells can differentially induce oligodendrogenesis and neurogenesis, respectively (Butovsky et al. 2006). Reducing neuroinflammation by specific drugs was further shown to restore or increase AN in different pathological models (Monje et al. 2003), although T cells even seem to influence hippocampal plasticity through effects on progenitor cells (Ziv et al. 2006).

Moreover, EL infection while immediately increasing proinflammatory cytokines in the hippocampus, induces only subtle reduction in hippocampal neurogenesis and limited effects on hippocampal functionality under basal 
conditions. However, after exposure to a "second hit" in adulthood, the history of early-life infection has been shown to have averse effects on cognitive functions and levels of neurogenesis (Bilbo et al. 2006, 2007; Bilbo and Schwarz 2009). Finally, it should be noted that psychological stress stimulates proinflammatory cytokine production in patients experiencing stress and anxiety. In depressed patients, increases in macrophage activity and the production of proinflammatory cytokines have been consistently reported (Dantzer et al. 2008).

\section{CONCLUDING REMARKS}

Stress, GCs, and inflammation all interfere with one or more of the phases of the neurogenic process. Their inhibitory effects can normalize after a recovery period, voluntary exercise, or antidepressant treatment. Although $\mathrm{AN}$ has been implicated in cognitive functions, in the regulation of mood and anxiety, and in the therapeutic effects of antidepressant drugs, its exact role in relation to the etiology of brain disorders like depression remains elusive. A reduced rate of neurogenesis may be indicative of impaired hippocampal plasticity but, by itself, reductions in AN per se are unlikely to produce depression. Lasting reductions in turnover rate of DG granule cells (e.g., programmed by EL events), however, will alter the overall composition of the DG cell population and can modify stress responsivity and thereby influence functioning of the adult hippocampal circuit as well as the vulnerability to develop brain disorders.

\section{REFERENCES}

Abrous DN, Koehl M, Le Moal M. 2005. Adult neurogenesis: From precursors to network and physiology. Physiol Rev 85: 523-569.

Aisa B, Tordera R, Lasheras B, Del Río J, Ramírez MJ. 2007. Cognitive impairment associated to HPA axis hyperac tivity after maternal separation in rats. Psychoneuroendocrinology 32: 256-266.

Alonso R, Griebel G, Pavone G, Stemmelin J, Le Fur G, Soubrie P. 2003. Blockade of $\mathrm{CRF}_{1}$ or $\mathrm{V}_{1 \mathrm{~b}}$ receptors reverses stress-induced suppression of neurogenesis in a mouse model of depression. Mol Psychiatry 9: 278-286.

Anacker C, Pariante CM. 2012. Can adult neurogenesis buffer stress responses and depressive behaviour? $\mathrm{Mol}$ Psychiatry 17: 9-10.
Anacker C, Cattaneo A, Luoni A, Musaelyan K, Zunszain PA, Milanesi E, Rybka J, Berry A, Cirulli F, Thuret S, et al. 2013. Glucocorticoid-related molecular signaling pathways regulating hippocampal neurogenesis. Neuropsychopharmacology 38: 872-883.

Balu DT, Lucki I. 2009. Adult hippocampal neurogenesis: Regulation, functional implications, and contribution to disease pathology. Neurosci Biobehav Rev 33: 232-252.

Banasr M, Duman RS. 2008. Glial loss in the prefrontal cortex is sufficient to induce depressive-like behaviors. Biol Psychiatry 64: 863-870.

Baram TZ, Davis EP, Obenaus A, Sandman CA, Small SL, Solodkin A, Stern H. 2012. Fragmentation and unpredictability of early-life experience in mental disorders. Am J Psychiatry 169: 907-915.

Battista D, Ferrari CC, Gage FH, Pitossi FJ. 2006. Neurogenic niche modulation by activated microglia: Transforming growth factor $\beta$ increases neurogenesis in the adult dentate gyrus. Eur J Neurosci 23: 83-93.

Belnoue L, Grosjean N, Ladevèze E, Abrous DN, Koehl M. 2013. Prenatal stress inhibits hippocampal neurogenesis but spares olfactory bulb neurogenesis. PLOS ONE 8: e72972.

Berkenbosch F, van Oers J, del Rey A, Tilders F, Besedovsky H. 1987. Corticotropin-releasing factor-producing neurons in the rat activated by interleukin-1. Science 238: 524-526.

Bilbo SD, Schwarz JM. 2009. Early-life programming of later-life brain and behavior: A critical role for the immune system. Front Behav Neurosci 3: 1-14

Bilbo SD, Rudy JW, Watkins LR, Maier SF. 2006. A behavioural characterization of neonatal infection-facilitated memory impairment in adult rats. Behav Brain Res 169: 39-47.

Bilbo SD, Newsum NJ, Sprunger DB, Watkins LR, Rudy JW, Maier SF. 2007. Differential effects of neonatal handling on early life infection-induced alterations in cognition in adulthood. Brain Behav Immun 21: 332-342.

Bland ST, Beckley JT, Young S, Tsang V, Watkins LR, Maier SF, Bilbo SD. 2010. Enduring consequences of early-life infection on glial and neural cell genesis within cognitive regions of the brain. Brain Behav Immun 24: 329-338.

Boku S, Toda H, Nakagawa S, Kato A, Inoue T, Koyama T, Hiroi N, Kusumi I. 2015. Neonatal maternal separation alters the capacity of adult neural precursor cells to differentiate into neurons via methylation of retinoic acid receptor gene promoter. Biol Psychiatry 77: 335-344.

Boldrini M, Underwood MD, Hen R, Rosoklija GB, Dwork AJ, John Mann J, Arango V. 2009. Antidepressants increase neural progenitor cells in the human hippocampus. Neuropsychopharmacology 34: 2376-2389.

Boldrini M, Hen R, Underwood MD, Rosoklija GB, Dwork AJ, Mann JJ, Arango V. 2012. Hippocampal angiogenesis and progenitor cell proliferation are increased with antidepressant use in major depression. Biol Psychiatry 72: 562-571.

Bourdeau I, Bard C, Noël B, Leclerc I, Cordeau M-P, Bélair M, Lesage J, Lafontaine L, Lacroix A. 2002. Loss of brain volume in endogenous Cushing's syndrome and its reversibility after correction of hypercortisolism. J Clin Endocrinol Metab 87: 1949-1954. 
P.J. Lucassen et al.

Bredy TW, Grant RJ, Champagne DL, Meaney MJ. 2003. Maternal care influences neuronal survival in the hippocampus of the rat. Eur J Neurosci 18: 2903-2909.

Brené S, Bjørnebekk A, Åberg E, Mathé AA, Olson L, Werme M. 2007. Running is rewarding and antidepressive. Physiol Behav 92: 136-140.

Bruel-Jungerman E, Lucassen PJ, Francis F. 2011. Cholinergic influences on cortical development and adult neurogenesis. Behav Brain Res 221: 379-388.

Brunson KL, Kramár E, Lin B, Chen Y, Colgin LL, Yanagihara TK, Lynch G, Baram TZ. 2005. Mechanisms of lateonset cognitive decline after early-life stress. J Neurosci 25: 9328-9338.

Butovsky O, Ziv Y, Schwartz A, Landa G, Talpalar AE, Pluchino S, Martino G, Schwartz M. 2006. Microglia activated by IL- 4 or IFN- $\gamma$ differentially induce neurogenesis and oligodendrogenesis from adult stem/progenitor cells. Mol Cell Neurosci 31: 149-160.

Cassidy EM, O'Keane V. 2000. Depression and interferon- $\alpha$ therapy. Br J Psychiatry 176: 494.

Chetty S, Friedman AR, Taravosh-Lahn K, Kirby ED, Mirescu C, Guo F, Krupik D, Nicholas A, Geraghty AC, Krishnamurthy A, et al. 2014. Stress and glucocorticoids promote oligodendrogenesis in the adult hippocampus. Mol Psychiatry 19: 1275-1283.

Coe CL, Kramer M, Czéh B, Gould E, Reeves AJ, Kirschbaum C, Fuchs E. 2003. Prenatal stress diminishes neurogenesis in the dentate gyrus of juvenile rhesus monkeys. Biol Psychiatry 54: 1025-1034.

Czéh B, Lucassen PJ. 2007. What causes the hippocampal volume decrease in depression? Are neurogenesis, glial changes and apoptosis implicated? Eur Arch Psychiatry Clin Neurosci 257: 250-260.

Czéh B, Michaelis T, Watanabe T, Frahm J, de Biurrun G, van Kampen M, Bartolomucci A, Fuchs E. 2001. Stress-induced changes in cerebral metabolites, hippocampal volume, and cell proliferation are prevented by antidepressant treatment with tianeptine. Proc Natl Acad Sci 98: 12796-12801.

Czéh B, Welt T, Fischer AK, Erhardt A, Schmitt W, Müller MB, Toschi N, Fuchs E, Keck ME. 2002. Chronic psychosocial stress and concomitant repetitive transcranial magnetic stimulation: Effects on stress hormone levels and adult hippocampal neurogenesis. Biol Psychiatry 52: $1057-1065$.

Czéh B, Pudovkina O, van der Hart MGC, Simon M, Heilbronner U, Michaelis T, Watanabe T, Frahm J, Fuchs E. 2005. Examining SLV-323, a novel NK1 receptor antagonist, in a chronic psychosocial stress model for depression. Psychopharmacology (Berl) 180: 548-557.

Czéh B, Simon M, Schmelting B, Hiemke C, Fuchs E. 2006. Astroglial plasticity in the hippocampus is affected by chronic psychosocial stress and concomitant fluoxetine treatment. Neuropsychopharmacology 31: 1616-1626.

Dantzer R, O'Connor JC, Freund GG, Johnson RW, Kelley KW. 2008. From inflammation to sickness and depression: When the immune system subjugates the brain. Nat Rev Neurosci 9: 46-56.

Datson NA, Speksnijder N, Mayer JL, Steenbergen PJ, Korobko O, Goeman J, de Kloet ER, Joëls M, Lucassen PJ. 2012. The transcriptional response to chronic stress and glucocorticoid receptor blockade in the hippocampal dentate gyrus. Hippocampus 22: 359-371.

de Kloet ER, Joëls M, Holsboer F. 2005. Stress and the brain: From adaptation to disease. Nat Rev Neurosci 6: 463-475.

Djavadian RL. 2004. Serotonin and neurogenesis in the hippocampal dentate gyrus of adult mammals. Acta Neurobiol Exp (Wars) 64: 189-200.

Domínguez-Escribà L, Hernández-Rabaza V, Soriano-Navarro M, Barcia JA, Romero FJ, García-Verdugo JM, Canales JJ. 2006. Chronic cocaine exposure impairs progenitor proliferation but spares survival and maturation of neural precursors in adult rat dentate gyrus. Eur J Neurosci 24: 586-594.

Droste SK, Gesing A, Ulbricht S, Müller MB, Linthorst ACE, Reul JMHM. 2003. Effects of long-term voluntary exercise on the mouse hypothalamic-pituitary-adrenocortical axis. Endocrinology 144: 3012-3023.

Ehninger D, Kempermann G. 2006. Paradoxical effects of learning the Morris water maze on adult hippocampal neurogenesis in mice may be explained by a combination of stress and physical activity. Genes Brain Behav 5: 2939.

Ekdahl CT, Kokaia Z, Lindvall O. 2009. Brain inflammation and adult neurogenesis: The dual role of microglia. $\mathrm{Neu}$ roscience 158: 1021-1029.

Erdmann G, Berger S, Schütz G. 2008. Genetic dissection of glucocorticoid receptor function in the mouse brain. $J$ Neuroendocrinol 20: 655-659.

Ernst C, Olson AK, Pinel JPJ, Lam RW, Christie BR. 2006. Antidepressant effects of exercise: Evidence for an adultneurogenesis hypothesis? JPsychiatry Neurosci 31: 84-92.

Fitzsimons CP, van Hooijdonk LWA, Schouten M, Zalachoras I, Brinks V, Zheng T, Schouten TG, Saaltink DJ, Dijkmans T, Steindler DA, et al. 2013. Knockdown of the glucocorticoid receptor alters functional integration of newborn neurons in the adult hippocampus and impairs fear-motivated behavior. Mol Psychiatry 18: 993-1005.

Fukuda A, Fukuda H, Swanpalmer J, Hertzman S, Lannering B, Marky I, Bjork-Eriksson T, Blomgren K. 2005. Agedependent sensitivity of the developing brain to irradiation is correlated with the number and vulnerability of progenitor cells. J Neurochem 92: 569-584.

Galea LAM. 2008. Gonadal hormone modulation of neurogenesis in the dentate gyrus of adult male and female rodents. Brain Res Rev 57: 332-341.

Ge S, Yang C-H, Hsu K-S, Ming G-L, Song H. 2007. A critical period for enhanced synaptic plasticity in newly generated neurons of the adult brain. Neuron 54: 559566.

Gould E, McEwen BS, Tanapat P, Galea LA, Fuchs E. 1997. Neurogenesis in the dentate gyrus of the adult tree shrew is regulated by psychosocial stress and NMDA receptor activation. J Neurosci 17: 2492-2498.

Greisen MH, Altar CA, Bolwig TG, Whitehead R, Wörtwein G. 2005. Increased adult hippocampal brain-derived neurotrophic factor and normal levels of neurogenesis in maternal separation rats. J Neurosci Res 79: 772-778.

Harris AP, Holmes MC, de Kloet ER, Chapman KE, Seckl JR. 2013. Mineralocorticoid and glucocorticoid receptor balance in control of HPA axis and behaviour. Psychoneuroendocrinology 38: 648-658. 
Heim C, Newport D, Mletzko T, Miller A, Nemeroff C. 2008 The link between childhood trauma and depression: Insights from HPA axis studies in humans. Psychoneuroendocrinology 33: 693-710.

Heine VM, Maslam S, Joëls M, Lucassen PJ. 2004a. Increased P27KIP1 protein expression in the dentate gyrus of chronically stressed rats indicates $G_{1}$ arrest involvement. Neuroscience 129: 593-601.

Heine VM, Maslam S, Zareno J, Joels M, Lucassen PJ. 2004b. Suppressed proliferation and apoptotic changes in the rat dentate gyrus after acute and chronic stress are reversible. Eur J Neurosci 19: 131-144.

Heine VM, Zareno J, Maslam S, Joels M, Lucassen PJ. 2005. Chronic stress in the adult dentate gyrus reduces cell proliferation near the vasculature and VEGF and Flk-1 protein expression. Eur J Neurosci 21: 1304-1314.

Hinwood M, Morandini J, Day TA, Walker FR. 2012. Evidence that microglia mediate the neurobiological effects of chronic psychological stress on the medial prefrontal cortex. Cereb Cortex 22: 1442-1454.

Hoffman KE, Yock TI. 2009. Radiation therapy for pediatric central nervous system tumors. J Child Neurol 24: $1387-$ 1396.

Holmes MM, Galea LAM, Mistlberger RE, Kempermann G. 2004. Adult hippocampal neurogenesis and voluntary running activity: Circadian and dose-dependent effects. J Neurosci Res 76: 216-222.

Hu P, Oomen C, van Dam AM, Wester J, Zhou JN, Joëls M, Lucassen PJ. 2012. A single-day treatment with mifepristone is sufficient to normalize chronic glucocorticoid induced suppression of hippocampal cell proliferation. PLOS ONE 7: e46224.

Huang Y, Coupland NJ, Lebel RM, Carter R, Seres P, Wilman AH, Malykhin NV. 2013. Structural changes in hippocampal subfields in major depressive disorder: A highfield magnetic resonance imaging study. Biol Psychiatry 74: $62-68$

Iosif RE, Ekdahl CT, Ahlenius $\mathrm{H}$, Pronk $\mathrm{CJH}$, Bonde S, Kokaia Z, Jacobsen S-EW, Lindvall O. 2006. Tumor necrosis factor receptor 1 is a negative regulator of progenitor proliferation in adult hippocampal neurogenesis. $J$ Neurosci 26: 9703-9712.

Ivy AS, Rex CS, Chen Y, Dubé C, Maras PM, Grigoriadis DE, Gall CM, Lynch G, Baram TZ. 2010. Hippocampal dysfunction and cognitive impairments provoked by chronic early-life stress involve excessive activation of CRH receptors. J Neurosci 30: 13005-13015.

Jacobs BL, van Praag H, Gage FH. 2000. Adult brain neurogenesis and psychiatry: A novel theory of depression. $\mathrm{Mol}$ Psychiatry 5: 262-269.

Jakubs K, Bonde S, Iosif RE, Ekdahl CT, Kokaia Z, Kokaia M, Lindvall O. 2008. Inflammation regulates functional integration of neurons born in adult brain. J Neurosci 28: 12477-12488.

Jessberger S, Gage FH. 2014. Adult neurogenesis: Bridging the gap between mice and humans. Trends Cell Biol 24: $558-563$.

Joca SRL, Ferreira FR, Guimarães FS. 2007. Modulation of stress consequences by hippocampal monoaminergic, glutamatergic and nitrergic neurotransmitter systems. Stress 10: 227-249.
Joels M, Baram TZ. 2009. The neuro-symphony of stress. Nat Rev Neurosci 10: 459-466.

Joels M, Karst H, Krugers HJ, Lucassen PJ. 2007. Chronic stress: Implications for neuronal morphology, function and neurogenesis. Front Neuroendocrinol 28: 72-96.

Joels M, Sarabdjitsingh RA, Karst H. 2012. Unraveling the time domains of corticosteroid hormone influences on brain activity: Rapid, slow, and chronic modes. Pharmacol Rev 64: 901-938.

Johansson S, Price J, Modo M. 2008. Effect of inflammatory cytokines on major histocompatibility complex expression and differentiation of human neural stem/progenitor cells. Stem Cells 26: 2444-2454.

Kaneko N, Okano H, Sawamoto K. 2006. Role of the cholinergic system in regulating survival of newborn neurons in the adult mouse dentate gyrus and olfactory bulb. Genes Cells 11: 1145-1159.

Kannangara TS, Lucero MJ, Gil-Mohapel J, Drapala RJ, Simpson JM, Christie BR, van Praag H. 2011. Running reduces stress and enhances cell genesis in aged mice. Neurobiol Aging 32: 2279-2286.

Kempermann G. 2012. New neurons for "survival of the fittest." Nat Rev Neurosci 13: 727-736.

Kempermann G, Krebs J, Fabel K. 2008. The contribution of failing adult hippocampal neurogenesis to psychiatric disorders. Curr Opin Psychiatry 21: 290-295.

Kempermann G, Fabel K, Ehninger D, Babu H, Leal-Galicia P, Garthe A, Wolf SA. 2010. Why and how physical activity promotes experience-induced brain plasticity. Front Neurosci 4: 189.

Kim JI, Lee JW, Lee YA, Lee DH, Han NS, Choi YK, Hwang BR, Kim BR, Kim HJ, Han JS. 2013. Sexual activity counteracts the suppressive effects of chronic stress on adult hippocampal neurogenesis and recognition memory. Brain Res 1538: 26-40.

Koehl M, van der Veen R, Gonzales D, Piazza PV, Abrous DN. 2012. Interplay of maternal care and genetic influences in programming adult hippocampal neurogenesis. Biol Psychiatry 72: 282-289.

Koo JW, Duman RS. 2008. IL-1 $\beta$ is an essential mediator of the antineurogenic and anhedonic effects of stress. Proc Natl Acad Sci 105: 751-756.

Koolhaas JM, Bartolomucci A, Buwalda B, de Boer SF, Flügge G, Korte SM, Meerlo P, Murison R, Olivier B, Palanza P, et al. 2011. Stress revisited: A critical evaluation of the stress concept. Neurosci Biobehav Rev 35: 1291-1301.

Korosi A, Naninck EFG, Oomen CA, Schouten M, Krugers H, Fitzsimons C, Lucassen PJ. 2012. Early-life stress mediated modulation of adult neurogenesis and behavior. Behav Brain Res 227: 400-409.

Kreisel T, Frank MG, Licht T, Reshef R, Ben-MenachemZidon O, Baratta MV, Maier SF, Yirmiya R. 2014. Dynamic microglial alterations underlie stress-induced depressive-like behavior and suppressed neurogenesis. Mol Psychiatry 19: 699-709.

Kretz O, Reichardt HM, Schütz G, Bock R. 1999. Corticotropin-releasing hormone expression is the major target for glucocorticoid feedback-control at the hypothalamic level. Brain Res 818: 488-491.

Kronenberg G, Bick-Sander A, Bunk E, Wolf C, Ehninger D, Kempermann G. 2006. Physical exercise prevents age-re- 


\section{P.J. Lucassen et al.}

lated decline in precursor cell activity in the mouse dentate gyrus. Neurobiol Aging 27: 1505-1513.

Lehmann ML, Brachman RA, Martinowich K, Schloesser RJ, Herkenham M. 2013. Glucocorticoids orchestrate divergent effects on mood through adult neurogenesis. $J$ Neurosci 33: 2961-2972.

Lemaire V, Koehl M, Le Moal M, Abrous DN. 2000. Prenatal stress produces learning deficits associated with an inhibition of neurogenesis in the hippocampus. Proc Natl Acad Sci 97: 11032-11037.

Leuner B. 2010. Parenting and plasticity. Trends Neurosci 33: 465-473.

Liston C, Cichon JM, Jeanneteau F, Jia Z, Chao MV, Gan W-B. 2013. Circadian glucocorticoid oscillations promote learning-dependent synapse formation and maintenance. Nature 16: 698-705.

Loi M, Koricka S, Lucassen PJ, Joëls M. 2014. Age- and sexdependent effects of early life stress on hippocampal neurogenesis. Front Endocrinol (Lausanne) 5: 13.

Loman MM, Gunnar MR; Early Experience, Stress, Neurobehavioral Development Center. 2010. Early experience and the development of stress reactivity and regulation in children. Neurosci Biobehav Rev 34: 867-876.

Lou S-J, Liu J-Y, Chang H, Chen P-J. 2008. Hippocampal neurogenesis and gene expression depend on exercise intensity in juvenile rats. Brain Res 1210: $48-55$.

Lucassen PJ, Bosch OJ, Jousma E, Krömer SA, Andrew R, Seckl JR, Neumann ID. 2009. Prenatal stress reduces postnatal neurogenesis in rats selectively bred for high, but not low, anxiety: Possible key role of placental $11 \beta$ hydroxysteroid dehydrogenase type 2. Eur J Neurosci 29: 97-103.

Lucassen PJ, Meerlo P, Naylor AS, van Dam AM, Dayer AG, Fuchs E, Oomen CA, Czéh B. 2010a. Regulation of adult neurogenesis by stress, sleep disruption, exercise and inflammation: Implications for depression and antidepressant action. Eur Neuropsychopharmacol 20: 1-17.

Lucassen PJ, Stumpel MW, Wang Q, Aronica E. 2010b. Decreased numbers of progenitor cells but no response to antidepressant drugs in the hippocampus of elderly depressed patients. Neuropharmacology 58: 940-949.

Lucassen PJ, Fitzsimons CP, Korosi A, Joëls M, Belzung C, Abrous DN. 2013a. Stressing new neurons into depression? Mol Psychiatry 18: 396-397.

Lucassen PJ, Naninck EF, van Goudoever JB, Fitzsimons C, Joels M, Korosi A. 2013b. Perinatal programming of adult hippocampal structure and function; emerging roles of stress, nutrition and epigenetics. Trends Neurosci 36: 621-631.

Lucassen PJ, Pruessner J, Sousa N, Almeida OF, van Dam AM, Rajkowska G, Swaab DF, Czéh B. 2014. Neuropathology of stress. Acta Neuropathol 127: 109-135.

Malberg JE, Duman RS. 2003. Cell proliferation in adult hippocampus is decreased by inescapable stress: Reversal by fluoxetine treatment. Neuropsychopharmacology 28: 1562-1571.

Manganas LN, Zhang X, Li Y, Hazel RD, Smith SD, Wagshul ME, Henn F, Benveniste H, Djuric PM, Enikolopov G, et al. 2007. Magnetic resonance spectroscopy identifies neural progenitor cells in the live human brain. Science 318: 980-985.
Marlatt MW, Potter MC, Lucassen PJ, van Praag H. 2012. Running throughout middle-age improves memory function, hippocampal neurogenesis, and BDNF levels in female C57BL/6J mice. Dev Neurobiol 72: 943-952.

Maselko J, Kubzansky L, Lipsitt L, Buka SL. 2011. Mother's affection at 8 months predicts emotional distress in adulthood. J Epidemiol Community Health 65: 621-625.

Mayer JL, Klumpers L, Maslam S, de Kloet ER, Joëls M, Lucassen PJ. 2006. Brief treatment with the glucocorticoid receptor antagonist mifepristone normalises the corticosterone-induced reduction of adult hippocampal neurogenesis. J Neuroendocrinol 18: 629-631.

Medina A, Seasholtz AF, Sharma V, Burke S, Bunney W, Myers RM, Schatzberg A, Akil H, Watson SJ. 2013. Glucocorticoid and mineralocorticoid receptor expression in the human hippocampus in major depressive disorder. $J$ Psychiatr Res 47: 307-314.

Miller JA, Nathanson J, Franjic D, Shim S, Dalley RA, Shapouri S, Smith KA, Sunkin SM, Bernard A, Bennett JL, et al. 2013. Conserved molecular signatures of neurogenesis in the hippocampal subgranular zone of rodents and primates. Development 140: 4633-4644.

Mirescu C, Gould E. 2006. Stress and adult neurogenesis. Hippocampus 16: 233-238.

Mirescu C, Peters JD, Gould E. 2004. Early life experience alters response of adult neurogenesis to stress. Nat Neurosci 7: 841-846.

Monje ML, Toda H, Palmer TD. 2003. Inflammatory blockade restores adult hippocampal neurogenesis. Science 302: $1760-1765$.

Montaron MF, Piazza PV, Aurousseau C, Urani A, Le Moal M, Abrous DN. 2003. Implication of corticosteroid receptors in the regulation of hippocampal structural plasticity. Eur J Neurosci 18: 3105-3111.

Morrens J, Van Den Broeck W, Kempermann G. 2012. Glial cells in adult neurogenesis. Glia 60: 159-174.

Morris GP, Clark IA, Zinn R, Vissel B. 2013. Microglia: A new frontier for synaptic plasticity, learning and memory, and neurodegenerative disease research. Neurobiol Learn Mem 105: 40-53.

Musaelyan K, Egeland M, Fernandes C, Pariante CM, Zunszain PA, Thuret S. 2014. Modulation of adult hippocampal neurogenesis by early-life environmental challenges triggering immune activation. Neural Plast 2014: 194396.

Nacher J, McEwen BS. 2006. The role of N-methyl-D-aspartate receptors in neurogenesis. Hippocampus 16: $267-$ 270.

Nair A, Vadodaria KC, Banerjee SB, Benekareddy M, Dias BG, Duman RS, Vaidya VA. 2007. Stressor-specific regulation of distinct brain-derived neurotrophic factor transcripts and cyclic AMP response element-binding protein expression in the postnatal and adult rat hippocampus. Neuropsychopharmacology 32: 1504-1519.

Naninck EFG, Hoeijmakers L, Kakava-Georgiadou N, Meesters A, Lazic SE, Lucassen PJ, Korosi A. 2015. Chronic early-life stress alters developmental and adult neurogenesis and impairs cognitive function in mice. Hippocampus 25: 309-328.

Naylor AS, Persson AI, Eriksson PS, Jonsdottir IH, Thorlin T. 2005. Extended voluntary running inhibits exercise- 
induced adult hippocampal progenitor proliferation in the spontaneously hypertensive rat. J Neurophysiol 93: 2406-2414.

Naylor AS, Bull C, Nilsson MKL, Zhu C, Bjork-Eriksson T, Eriksson PS, Blomgren K, Georg Kuhn H. 2008. Voluntary running rescues adult hippocampal neurogenesis after irradiation of the young mouse brain. Proc Natl Acad Sci 105: 14632-14637.

Oomen CA, Mayer JL, de Kloet ER, Joels M, Lucassen PJ. 2007. Brief treatment with the glucocorticoid receptor antagonist mifepristone normalizes the reduction in neurogenesis after chronic stress. Eur J Neurosci 26: 33953401.

Oomen CA, Girardi CEN, Cahyadi R, Verbeek EC, Krugers H, Joels M, Lucassen PJ. 2009. Opposite effects of early maternal deprivation on neurogenesis in male versus female rats. PLoS ONE 4: e3675.

Oomen CA, Soeters H, Audureau N, Vermunt L, van Hasselt FN, Manders EMM, Joels M, Lucassen PJ, Krugers H. 2010. Severe early life stress hampers spatial learning and neurogenesis, but improves hippocampal synaptic plasticity and emotional learning under high-stress conditions in adulthood. J Neurosci 30: 6635-6645.

Oomen CA, Soeters H, Audureau N, Vermunt L, van Hasselt FN, Manders EM, Joëls M, Krugers H, Lucassen PJ. 2011. Early maternal deprivation affects dentate gyrus structure and emotional learning in adult female rats. Psychopharmacology (Berl) 214: 249-260.

Oomen CA, Bekinschtein P, Kent BA, Saksida LM, Bussey TJ. 2014. Adult hippocampal neurogenesis and its role in cognition. WIREs Cogn Sci 5: 573-587.

Parihar VK, Hattiangady B, Kuruba R, Shuai B, Shetty AK. 2011. Predictable chronic mild stress improves mood, hippocampal neurogenesis and memory. Mol Psychiatry 16: $171-183$.

Perera TD, Dwork AJ, Keegan KA, Thirumangalakudi L, Lipira CM, Joyce N, Lange C, Higley JD, Rosoklija G, Hen R, et al. 2011. Necessity of hippocampal neurogenesis for the therapeutic action of antidepressants in adult nonhuman primates. PLOS ONE 6: e17600.

Pham K, Nacher J, Hof PR, McEwen BS. 2003. Repeated restraint stress suppresses neurogenesis and induces biphasic PSA-NCAM expression in the adult rat dentate gyrus. Eur J Neurosci 17: 879-886.

Pruessner JC, Dedovic K, Pruessner M, Lord C, Buss C, Collins L, Dagher A, Lupien SJ. 2010. Stress regulation in the central nervous system: Evidence from structural and functional neuroimaging studies in human populations-2008 Curt Richter Award Winner. Psychoneuroendocrinology 35: 179-191.

Qi X-R, Kamphuis W, Wang S, Wang Q, Lucassen PJ, Zhou J-N, Swaab DF. 2013. Aberrant stress hormone receptor balance in the human prefrontal cortex and hypothalamic paraventricular nucleus of depressed patients. Psychoneuroendocrinology 38: 863-870.

Qian X, Droste SK, Lightman SL, Reul JMHM, Linthorst ACE. 2012. Circadian and ultradian rhythms of free glucocorticoid hormone are highly synchronized between the blood, the subcutaneous tissue, and the brain. Endocrinology 153: 4346-4353.

Ravizza T, Noé F, Zardoni D, Vaghi V, Sifringer M, Vezzani A. 2008. Interleukin converting enzyme inhibition impairs kindling epileptogenesis in rats by blocking astrocytic IL-1 $\beta$ production. Neurobiol Dis 31: 327-333.

Reif A, Fritzen S, Finger M, Strobel A, Lauer M. 2006. Neural stem cell proliferation is decreased in schizophrenia, but not in depression. Mol Psychiatry 11: 514-522.

Revest JM, Dupret D, Koehl M, Funk-Reiter C, Grosjean N, Piazza PV, Abrous DN. 2009. Adult hippocampal neurogenesis is involved in anxiety related behaviors. Mol Psychiatry 14: 959-967.

Rhen T, Cidlowski JA. 2005. Antiinflammatory action of glucocorticoids-New mechanisms for old drugs. $N$ Engl J Med 353: 1711-1723.

Ridder S, Chourbaji S, Hellweg R, Urani A, Zacher C, Schmid W, Zink M, Hörtnagl H, Flor H, Henn FA, et al. 2005. Mice with genetically altered glucocorticoid receptor expression show altered sensitivity for stress-induced depressive reactions. J Neurosci 25: 6243-6250.

Sahay A, Hen R. 2007. Adult hippocampal neurogenesis in depression. Nat Neurosci 10: 1110-1115.

Sánchez MM, Young LJ, Plotsky PM, Insel TR. 2000. Distribution of corticosteroid receptors in the rhesus brain: Relative absence of glucocorticoid receptors in the hippocampal formation. J Neurosci 20: 4657-4668.

Sapolsky RM, Krey LC, McEwen BS. 1985. Prolonged glucocorticoid exposure reduces hippocampal neuron number: Implications for aging. J Neurosci 5: 1222-1227.

Sapolsky RM, Uno H, Rebert CS, Finch CE. 1990. Hippocampal damage associated with prolonged glucocorticoid exposure in primates. J Neurosci 10: 2897-2902.

Schmidt HD, Duman RS. 2007. The role of neurotrophic factors in adult hippocampal neurogenesis, antidepressant treatments and animal models of depressive-like behavior. Behav Pharmacol 18: 391-418.

Schoenfeld TJ, Gould E. 2013. Differential effects of stress and glucocorticoids on adult neurogenesis. Curr Top Behav Neurosci 15: 139-164.

Schouten M, Buijink MR, Lucassen PJ, Fitzsimons CP. 2012. New neurons in aging brains: Molecular control by small non-coding RNAs. Front Neurosci 6: 25.

Sierra A, Encinas JM, Deudero JJP, Chancey JH, Enikolopov G, Overstreet-Wadiche LS, Tsirka SE, Maletic-Savatic M. 2010. Microglia shape adult hippocampal neurogenesis through apoptosis-coupled phagocytosis. Cell Stem Cell 7: 483-495.

Singh AK, Gupta S, Jiang Y, Younus M, Ramzan M. 2009. In vitro neurogenesis from neural progenitor cells isolated from the hippocampus region of the brain of adult rats exposed to ethanol during early development through their alcohol-drinking mothers. Alcohol Alcohol 44: $185-198$.

Skaper SD. 2007. The brain as a target for inflammatory processes and neuroprotective strategies. Ann NY Acad Sci 1122: 23-34.

Snyder JS, Soumier A, Brewer M, Pickel J, Cameron HA. 2011. Adult hippocampal neurogenesis buffers stress responses and depressive behaviour. Nature 476: 458-461.

Sousa N, Almeida OF, Holsboer F, Paula-Barbosa MM, Madeira MD. 1998. Maintenance of hippocampal cell numbers in young and aged rats submitted to chronic unpredictable stress. Comparison with the effects of corticosterone treatment. Stress 2: 237-249. 
P.J. Lucassen et al.

Sousa N, Cerqueira JJ, Almeida O. 2008. Corticosteroid receptors and neuroplasticity. Brain Res Rev 57: 561-570.

Spadafora R, Gonzalez FF, Derugin N, Wendland M, Ferriero D, McQuillen P. 2010. Altered fate of subventricular zone progenitor cells and reduced neurogenesis following neonatal stroke. Dev Neurosci 32: 101-113.

Spulber S, Oprica M, Bartfai T, Winblad B, Schultzberg M. 2008. Blunted neurogenesis and gliosis due to transgenic overexpression of human soluble IL-1ra in the mouse. Eur J Neurosci 27: 549-558.

Surget A, Saxe M, Leman S, Ibarguen-Vargas Y, Chalon S, Griebel G, Hen R, Belzung C. 2008. Drug-dependent requirement of hippocampal neurogenesis in a model of depression and of antidepressant reversal. Biol Psychiatry 64: 293-301.

Surget A, Tanti A, Leonardo ED, Laugeray A, Rainer Q, Touma C, Palme R, Griebel G, Ibarguen-Vargas Y, Hen R, et al. 2011. Antidepressants recruit new neurons to improve stress response regulation. Mol Psychiatry 16: 1177-1188.

Suri D, Veenit V, Sarkar A, Thiagarajan D, Kumar A, Nestler EJ, Galande S, Vaidya VA. 2013. Early stress evokes agedependent biphasic changes in hippocampal neurogenesis, Bdnf expression, and cognition. Biol Psychiatry 73: 658-666.

Swaab D, Bao A, Lucassen P. 2005. The stress system in the human brain in depression and neurodegeneration. Ageing Res Rev 4: 141-194.

Takamura N, Nakagawa S, Masuda T, Boku S, Kato A, Song N, An Y, Kitaichi Y, Inoue T, Koyama T, et al. 2014. The effect of dopamine on adult hippocampal neurogenesis. Prog Neuropsychopharmacol Biol Psychiatry 50: 116-124.

Tauber SC, Bunkowski S, Schlumbohm C, Rühlmann M, Fuchs E, Nau R, Gerber J. 2008. No long-term effect two years after intrauterine exposure to dexamethasone on dentate gyrus volume, neuronal proliferation and differentiation in common marmoset monkeys. Brain Pathol 18: 497-503.

Teicher MH, Anderson CM, Polcari A. 2012. Childhood maltreatment is associated with reduced volume in the hippocampal subfields CA3, dentate gyrus, and subiculum. Proc Natl Acad Sci 109: 563-572.

Ursin H, Eriksen HR. 2004. The cognitive activation theory of stress. Psychoneuroendocrinology 29: 567-592.

Vallières L, Campbell IL, Gage FH, Sawchenko PE. 2002. Reduced hippocampal neurogenesis in adult transgenic mice with chronic astrocytic production of interleukin-6. J Neurosci 22: 486-492.

Van Bokhoven P, Oomen CA, Hoogendijk WJ, Smit AB, Lucassen PJ, Spijker S. 2011. Reduction in hippocampal neurogenesis after social defeat is long-lasting and responsive to late antidepressant treatment. Eur J Neurosci 33: $1833-1840$.

Vinkers CH, Joëls M, Milaneschi Y, Kahn RS, Penninx BW, Boks MP. 2014. Stress exposure across the life span cumulatively increases depression risk and is moderated by neuroticism. Depress Anxiety 31: 737-745.

Vivar C, Potter MC, van Praag H. 2013. All about running: Synaptic plasticity, growth factors and adult hippocampal neurogenesis. Curr Top Behav Neurosci 15: 189-210.
Vollmayr B, Simonis C, Weber S, Gass P, Henn F. 2003. Reduced cell proliferation in the dentate gyrus is not correlated with the development of learned helplessness. Biol Psychiatry 54: 1035-1040.

Wachs F-P, Winner B, Couillard-Despres S, Schiller T, Aigner R, Winkler J, Bogdahn U, Aigner L. 2006. Transforming growth factor- $\beta 1$ is a negative modulator of adult neurogenesis. J Neuropathol Exp Neurol 65: 358-370.

Wang Q, Joëls M, Swaab DF, Lucassen PJ. 2012. Hippocampal GR expression is increased in elderly depressed females. Neuropharmacology 62: 527-533.

Wang Q, Van Heerikhuize J, Aronica E, Kawata M, Seress L, Joels M, Swaab DF, Lucassen PJ. 2013. Glucocorticoid receptor protein expression in human hippocampus; stability with age. Neurobiol Aging 34: 1662-1673.

Wang Q, Verweij EWE, Krugers HJ, Joëls M, Swaab DF, Lucassen PJ. 2014. Distribution of the glucocorticoid receptor in the human amygdala; changes in mood disorder patients. Brain Struct Funct 219: 1615-1626.

Weaver ICG, Grant RJ, Meaney MJ. 2002. Maternal behavior regulates long-term hippocampal expression of BAX and apoptosis in the offspring. J Neurochem 82: 998-1002.

Wei Q, Hebda-Bauer EK, Pletsch A, Luo J, Hoversten MT, Osetek AJ, Evans SJ, Watson SJ, Seasholtz AF, Akil H. 2007. Overexpressing the glucocorticoid receptor in forebrain causes an aging-like neuroendocrine phenotype and mild cognitive dysfunction. J Neurosci 27: 88368844.

Wilson CB. 2014. Predator exposure/psychosocial stress animal model of post-traumatic stress disorder modulates neurotransmitters in the rat hippocampus and prefrontal cortex. PLoS ONE 9: e89104.

Wong EYH, Herbert J. 2004. The corticoid environment: A determining factor for neural progenitors' survival in the adult hippocampus. Eur J Neurosci 20: 2491-2498.

Wong EYH, Herbert J. 2005. Roles of mineralocorticoid and glucocorticoid receptors in the regulation of progenitor proliferation in the adult hippocampus. Eur J Neurosci 22: 785-792.

Wu MV, Shamy JL, Bedi G, Choi CW, Wall MM, Arango V, Boldrini M, Foltin RW, Hen R. 2014. Impact of social status and antidepressant treatment on neurogenesis in the baboon hippocampus. Neuropsychopharmacology 39: 1861-1871.

Zhao C, Deng W, Gage FH. 2008. Mechanisms and functional implications of adult neurogenesis. Cell 132: 645-60.

Zhu C, Gao J, Karlsson N, Li Q, Zhang Y. 2010. Isoflurane anesthesia induced persistent, progressive memory impairment, caused a loss of neural stem cells, and reduced neurogenesis in young, but not adult rodents. J Cereb Blood Flow Metab 30: 1017-1030.

Ziv Y, Avidan H, Pluchino S, Martino G, Schwartz M. 2006. Synergy between immune cells and adult neural stem/ progenitor cells promotes functional recovery from spinal cord injury. Proc Natl Acad Sci 103: 13174-13179.

Zunszain PA, Anacker C, Cattaneo A, Choudhury S, Musaelyan K, Myint AM, Thuret S, Price J, Pariante CM. 2012. Interleukin-1 $\beta$ : A new regulator of the kynurenine pathway affecting human hippocampal neurogenesis. Neuropsychopharmacology 37: 939-949. 


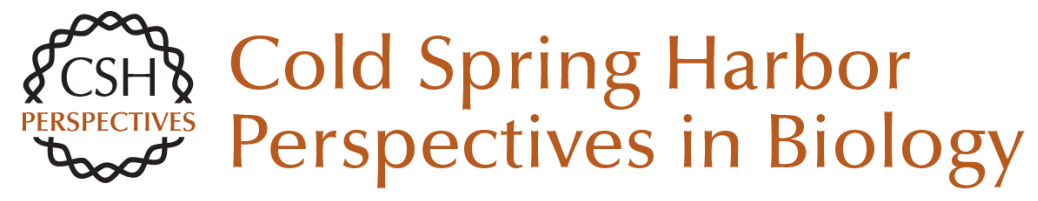

\section{Regulation of Adult Neurogenesis and Plasticity by (Early) Stress, Glucocorticoids, and Inflammation}

Paul J. Lucassen, Charlotte A. Oomen, Eva F.G. Naninck, Carlos P. Fitzsimons, Anne-Marie van Dam, Boldizsár Czeh and Aniko Korosi

Cold Spring Harb Perspect Biol 2015; doi: 10.1101/cshperspect.a021303

\section{Subject Collection Neurogenesis}

Adult Neurogenesis and Psychiatric Disorders

Eunchai Kang, Zhexing Wen, Hongjun Song, et al.

Neuronal Circuitry Mechanisms Regulating Adult

Mammalian Neurogenesis Juan Song, Reid H.J. Olsen, Jiaqi Sun, et al.

Neurogenesis in the Developing and Adult Brain

--Similarities and Key Differences

Magdalena Götz, Masato Nakafuku and David Petrik

Genetics and Epigenetics in Adult Neurogenesis Jenny Hsieh and Xinyu Zhao

The Adult Ventricular-Subventricular Zone (V-SVZ) and Olfactory Bulb (OB) Neurogenesis Daniel A. Lim and Arturo Alvarez-Buylla

Diversity of Neural Precursors in the Adult Mammalian Brain Michael A. Bonaguidi, Ryan P. Stadel, Daniel A. Berg, et al.

Detection and Phenotypic Characterization of Adult Neurogenesis

H. Georg Kuhn, Amelia J. Eisch, Kirsty Spalding, et al.

Maturation and Functional Integration of New Granule Cells into the Adult Hippocampus

Nicolas Toni and Alejandro F. Schinder
Adult Olfactory Bulb Neurogenesis

Pierre-Marie Lledo and Matt Valley

Adult Neurogenesis in Fish Julia Ganz and Michael Brand

In Vitro Models for Neurogenesis Hassan Azari and Brent A. Reynolds Engineering of Adult Neurogenesis and
Gliogenesis

Benedikt Berninger and Sebastian Jessberger

Computational Modeling of Adult Neurogenesis James B. Aimone

Control of Adult Neurogenesis by Short-Range

Morphogenic-Signaling Molecules Youngshik Choe, Samuel J. Pleasure and Helena Mira

Adult Neurogenesis: An Evolutionary Perspective Gerd Kempermann

Epilepsy and Adult Neurogenesis

Sebastian Jessberger and Jack M. Parent

For additional articles in this collection, see http://cshperspectives.cshlp.org/cgi/collection/

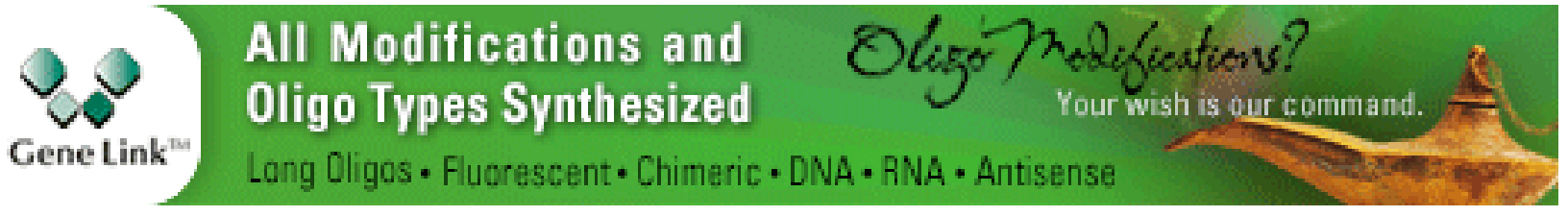


For additional articles in this collection, see http://cshperspectives.cshlp.org/cgi/collection/

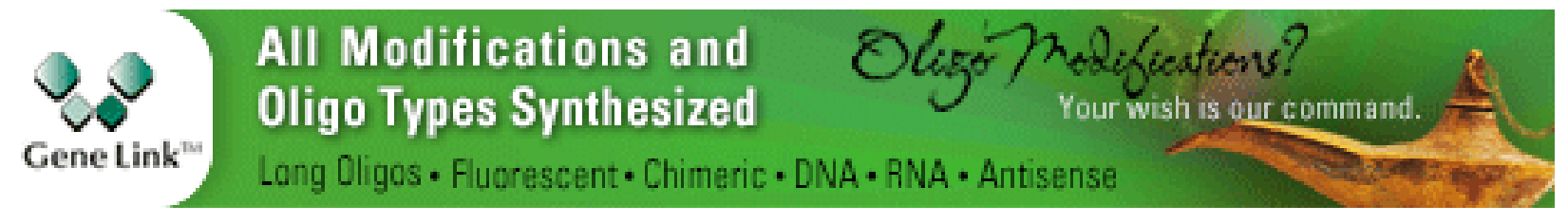

Copyright @ 2015 Cold Spring Harbor Laboratory Press; all rights reserved 